\title{
Parameter Prediction of Friction Stir Welding Aluminium Alloy by Anova Technique
}

\author{
Arjun Verma ${ }^{1}$, Ankit kumar Dubey ${ }^{2}$ \\ ${ }^{I} M$ - Tech scholar,Department of Mechanical Engineering,GD Rungta college of Engineering \& Technology, \\ Bhilai (C.G.) \\ ${ }^{2}$ Assistant Professor, Department of Mechanical Engineering,GD Rungta college of Engineering \& Technology, \\ Bhilai (C.G.)
}

\begin{abstract}
Friction stir welding can be controlled by different parameters like rotational speed, feed rate and welding medium. In this research, friction stir welding of marine grade Aluminium alloy 5083 is investigated and is welded with high strength Aluminium alloy 2024 T3. Friction stir welding (FSW) was selected for the joining of lap and butt welded parts having $150 \times 50 \times 5 \mathrm{~mm}$ thick sheets each. The present work shows that composite materials have highest effect on mechanical properties of the specimens taken from welded zone. They were tested for mechanical properties such as tensile strength and Rockwell hardness respectively. The parameter for Charpy impact test and tensile stress predict the significant by ANOVA analysis.
\end{abstract}

Keywords: Friction Stir welding (FSW), Aluminium alloy, Tensile Strength, Rockwell Hardness.

\section{Introduction}

Butt welding Aluminium alloys has received much of the focus. Butt welding materials of different thickness as well as tapered sections can also be performed. FSW can be used in some applications to reduce weight by replacing fasteners and reducing part count, which can actually reduce costs. It is necessary first to discuss the convention used for referring to locations within friction stir welds. Since friction stir welds are asymmetrical, it is necessary to accurately convey which side is intended when referring to specific locations within a weld with respect to the tool rotation and feed directions. The following convention will be used in the discussions to follow. The opposite side, where the motion of the surface of the welding tool opposes the feed direction, is referred to as the retreating side. A terminology convention that is also used refers to the advancing and retreating sides as the shear side and the flow side, but since this convention makes assumptions about the material flow, the more generic terminology will be used here.

There are two tool speeds to be considered in friction-stir welding; how fast the tool rotates and how quickly it traverses the interface. These two parameters have considerable importance and must be chosen with care to ensure a successful and efficient welding cycle. The relationship between the welding speeds and the heat input during welding is complex but, in general, it can be said that increasing the rotation speed or decreasing the traverse speed will result in a hotter weld. In order to produce a successful weld it is necessary that the material surrounding the tool is hot enough to enable the extensive plastic flow required and minimize the forces acting on the tool.

\section{Review Work}

Kumbhar and Bhanumurthy (2012) carried out experiment in FSW to join Aluminium alloys AA6061 and AA5052 at various combinations of tool rotation speeds and tool transverse speed. It was seen that the interdiffusion of the alloying elements and development of similar orientations in the nugget could have contributed of the better tensile properties of the friction stir welded AA5052-AA6061 specimen.[1]

Studies were performed by Litwinski to examine the effect of travel speed on the tensile properties of FSW samples. Samples were naturally and artificially aged for various times from one hour to over two and a half years. The longest natural aging at 2.5 years resulted in higher strength and elongation than the natural aging for shorter times. Increasing travel speed was also found to increase ultimate and yield strengths in all types of aging. [2]

Lee et al. Aluminium alloy 356 samples were friction stir welded at $1600 \mathrm{rpm}$ rotational speed, a feed rate ranging between 87 to $342 \mathrm{~mm} / \mathrm{min}$ and an angle of $3^{\circ}$ with respect to the welded plate. It was also noted that all the specimens were fractured at the unaffected base material rather than the welded material [3].

Masayuki Aonuma and Kazuhiro Nakata (2012) joined ZK60 magnesium alloy and titanium by friction stir welding. In this study the effect of alloying elements on the microstructure of the joint was examined. It was found that $\mathrm{Zn}$ and $\mathrm{Zr}$ of alloying elements of $\mathrm{Mg}-\mathrm{ZnZr}$ alloy improved the tensile strength of titanium and magnesium joints by forming the thin reaction layer at the joint interface.[4] 
McQueen et al. investigated the effect of friction stir welding on Aluminium alloy 6065 in terms of mechanical properties and microstructure. The only unsatisfying result in McQueen et al.'s study is that the ductility decreased to below $50 \%$ of the unprocessed alloy.[5]

\section{Objective Of Work}

Many of the problems associated with cooling from the liquid phase are avoided with friction stir welding because it is a solid state process. While this welding process typically produces welds which are as strong and ductile as the parent material, certain welding parameters have been found to produce a sharp decrease in strength and ductility in the welds. This problem has been attributed to a retained or residual oxide defect, caused by incomplete breakup of the oxide layer during welding, but the exact cause are not known and needed to be determined.

\section{Methodology}

Although research has previously been conducted on the FSW behaviour of aluminium alloys, very little work has been done on inhomogeneous welds. The sample preparation procedure followed in this study is also presented including polishing and etching. Aluminium Alloy 5083 and 2024 T3 will be taken with typical composition shown in Table 1. In an effort to reduce weight, AA 5083 was developed to replace much of the AA 2024 T3 in use on the space shuttle.

Table 1: Component of Aluminium Alloy

\begin{tabular}{|c|c|c|}
\hline Component & AA 5083 \% & AA 2024 T3 \% \\
\hline Magnesium $(\mathrm{Mg})$ & $4.00-4.90$ & $1.2-1.8$ \\
\hline Manganese $(\mathrm{Mn})$ & $0.40-1.00$ & $0.3-0.9$ \\
\hline Iron $(\mathrm{Fe})$ & 0.40 & $0.1-0.5$ \\
\hline Silicon $(\mathrm{Si})$ & $0.0-0.40$ & $0.1-0.5$ \\
\hline Titanium $(\mathrm{Ti})$ & $0.05-0.25$ & $0.0-0.15$ \\
\hline Chromium $(\mathrm{Cr})$ & $0.05-0.25$ & $0.0-0.1$ \\
\hline Copper $(\mathrm{Cu})$ & 0.10 & $3.8-4.9$ \\
\hline Zinc $(\mathrm{Zn})$ & $0.0-0.10$ & $0.1-0.3$ \\
\hline Other $(\mathrm{Each})$ & $0.0-0.05$ & $0.1-0.15$ \\
\hline Aluminium $(\mathrm{Al})$ & $92.2-94.6$ & $90.7-94.7$ \\
\hline Zirconium $(\mathrm{Zr})$ & -------- & 0 to 0.2 \\
\hline
\end{tabular}

\section{Process Work}

Design of experiment (DOE) is important as a formal way of maximizing information gained while minimizing resources required. It has more to offer than 'one change at a time' experimental methods, because it allows a judgment on the significance to the output of input variables acting alone, as well input variables acting in combination with one another. The specimens used in this work are made of marine grade Aluminium alloy 5083 and 2024 T3 specifications and compositions are discussed in Table 1. The samples used are $150 \mathrm{~mm}$ in length, $50 \mathrm{~mm}$ in width and $5 \mathrm{~mm}$ thick. The specimens used are cut from $5 \mathrm{~mm}$ sheets; holes are drilled on the sides of the specimen to allow clamping it in the specially designed tank for submerged friction stir processing.Perform friction stir weld on two dissimilar Aluminium Alloy as per the generation of design of experiment (DOE). Measure the Tensile Test and Charpy Test of weld joint and predict the parameter by ANOVA test. Tensile strength of the FSW joints were evaluated by conducting test on Universal Testing Machine and Charpy Test results is presented in Table2.

Table 2: Response Table

\begin{tabular}{|c|c|c|c|c|c|}
\hline S No. & $\mathbf{R S}$ & WS & SD & (T) $\mathrm{N} / \mathrm{mm}^{2}$ & (I) $\mathrm{MPa}$ \\
\hline 1 & 400 & 40 & 18 & 179 & 53 \\
\hline 2 & 400 & 45 & 19 & 184 & 58 \\
\hline 3 & 400 & 50 & 20 & 186 & 59 \\
\hline 4 & 450 & 40 & 19 & 178 & 63 \\
\hline 5 & 450 & 45 & 20 & 182 & 58 \\
\hline 6 & 450 & 50 & 18 & 186 & 67 \\
\hline 7 & 500 & 40 & 20 & 193 & 62 \\
\hline 8 & 500 & 45 & 18 & 197 & 59 \\
\hline 9 & 500 & 50 & 19 & 189 & 64 \\
\hline
\end{tabular}

Anova result for tensile test are shown in table 3 and their result of efficient parameter are shown in fig 1 
Table 3: ANOVA result of Tensile Test

\begin{tabular}{|c|l|l|c|l|c|c|}
\hline S & DF & Seq SS & Adj SS & Adj MS & F & P \\
\hline RS & 2 & 222.00 & 222.00 & 111.00 & 6.80 & 0.128 \\
\hline WS & 2 & 32.67 & 32.67 & 16.33 & 1.00 & 0.500 \\
\hline SD & 2 & 24.67 & 24.67 & 12.33 & 0.76 & 0.570 \\
\hline RE & 2 & 32.67 & 32.67 & 16.33 & & \\
\hline Total & 8 & 312.00 & & & & \\
\hline
\end{tabular}

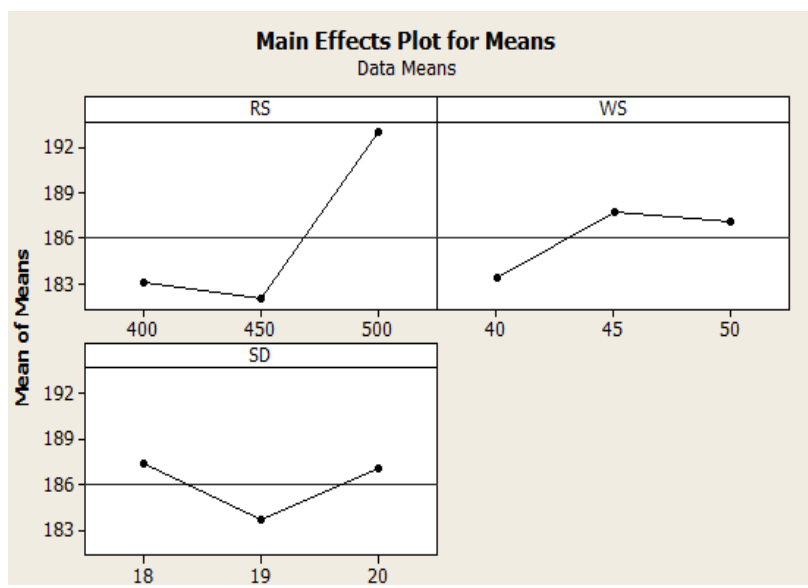

Fig 1 Mean Effect plot of Tensile Test

ANOVA result for Tensile Test are shown in table 4 and their result of efficient parameter are shown in fig 2

Table 4 ANOVA result of Impact Test

\begin{tabular}{|l|l|l|l|l|l|l|}
\hline S & DF & Seq SS & Adj SS & Adj MS & F & P \\
\hline RS & 2 & 62.000 & 62.00 & 31.000 & 2.58 & 0.279 \\
\hline WS & 2 & 42.000 & 42.00 & 21.000 & 1.75 & 0.364 \\
\hline SD & 2 & 8.000 & 8.000 & 4.000 & 0.33 & 0.750 \\
\hline RE & 2 & 24.000 & 24.00 & 12.000 & & \\
\hline Total & 8 & 136.000 & & & & \\
\hline
\end{tabular}

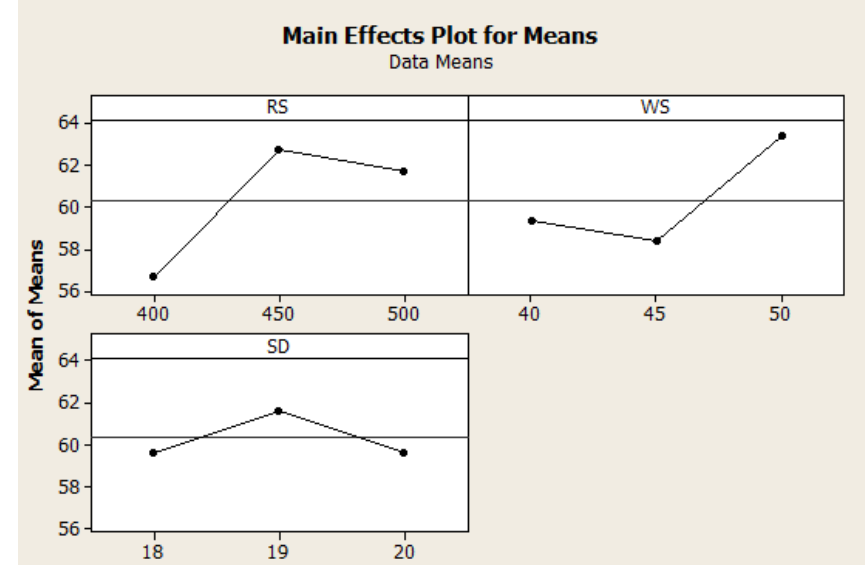

Fig 2 Mean Effect plot of Impact Test

As seen in the fig 1 the optimum parameter for tensile stress are rotational speed is 500rpm, welding speed is $45 \mathrm{~mm} / \mathrm{min}$ and shoulder diameter is $18 \mathrm{~mm}$. For impact test their optimum parameter is different that is rotational speed is $450 \mathrm{rpm}$, welding speed is $50 \mathrm{~mm} / \mathrm{min}$ and shoulder diameter is $19 \mathrm{~mm}$. in both case seen that all parameter are different for its individual outputso for prediction rotational speed, welding speed and shoulder diameter select the lowest $\mathrm{P}$ value from the table 3 and table 4 . The lowest $\mathrm{P}$ value for rotational speed as comparing in both tableis 0.128 for tensile stress so $500 \mathrm{rpm}$ is predicted for rotational speed. Similarly welding speed is predicted $50 \mathrm{~mm} / \mathrm{min}$ and for shoulder diameter are 18 . ANOVA prediction results for its individual parameter are shown in Table 5. 
Table 5 Individual Parameter

\begin{tabular}{|l|l|l|l|}
\hline Strength & RS & WS & SD \\
\hline Tensile & 500 & 45 & 18 \\
\hline Hardness & 450 & 50 & 19 \\
\hline
\end{tabular}

\section{Conclusion}

Perform friction stir weld on two dissimilar Aluminium Alloy as per the generation of design of experiment. Measure the tensile test and charpy test of weld joint as per DOE. Finally predict the parameter for optimum welding. Future work can be proceed on these work to optimize the factor and their level by some advance optimizing technique.

\section{Reference}

[1]. Kumbhar N T and Bhanumurthy K (2012), "Friction StirWelding of Al 5052 with Al 6061 Alloys", Journal of Metallurgy, Vol. 2012, Article ID 303756, p. 7, doi:10.1155/2012/303756

[2]. Litwinski, E. Effect of FSW Process and Parameters on Corrosion Susceptibility, Microscopy and Microanalysis 2005 in Honolulu, Hawaii, USA, July 31--August 4, 2005

[3]. $\quad$ Lee W.B., Y.M. Yeon, and S.B. Jung, "The improvement of mechanical properties of friction-stir-welded A356 Al alloy," Materials Science and Engineering, A355, pp. 154-159, 2003.

[4]. Masayuki Aonumaa and Kazuhiro Nakatab (2012), "Dissimilar metal joining of ZK60 magnesium alloy and titanium by friction stir welding", Materials Science and Engineering B, Vol. 177, pp. 543548

[5]. McQueen H.J., M. Cabibbo, E. Evangelista, S. Spigarelli, M. Di Paola, and A. Falchero, "Microstructure and mechanical properties of AA6056 friction stir welded plate," Metallurgical Science and Technology, pp. 22-30, 2007.

[6]. M. Ericsson and R. Sandstrom, Influence of welding speed on the fatigue of friction stir welding and comparison with MIG and TIG, International Journal of Fatigue, 25(2003), 1379-1387.

[7]. M. Guricic, G. Arakera, B. Pandurangan, A. hariharan, C. F. Yen, and B. A. chesseman, Development of a robust and cost-effective friction stir welding process for use in advanced military vehicles, J. of material engineering and performance, 20(2011),11-23.

[8]. M. Jayaraman, R. Sivasubramanian, V. Balasubramanian, and S. Babu, Optimization of friction stir welding process parameters to weld cast Aluminium alloy A413- an experimental approach, Intr. J of cast metal research, 22(2009), 367-373

[9]. S. Kanwer, Arora, S. pandey, M. Schaper, and R. Kumar, Effect of process parameters on friction stir welding of Aluminium alloy 2219-T87, Int. J. adv. Manu. Tech., 50(2010), 941-952.

[10]. Schneider, J. A., Nunes, Jr., A. C., "Characterization of Plastic Flow and Resulting Micro Textures in a Friction Stir Weld," Met. Trans. B., p. 777-783, 2004.

[11]. Sutton M.A., B. Yang, A.P. Reynolds and R. Taylor, "Microstructural studies of friction stir welds in 2024-T3 Aluminium," Materials Science and Engineering, A323, pp. 160-166, 2002. 